\title{
Toxic Epidermal Necrolysis, CTCAE
}

National Cancer Institute

\section{Source}

National Cancer Institute. Toxic Epidermal Necrolysis, CTCAE. NCI Thesaurus. Code C143880.

A disorder characterized by greater than $30 \%$ total body skin area separation of dermis.

The syndrome is thought to be a hypersensitivity complex affecting the skin and the mucous membranes. 